\title{
A non-selective (amitriptyline), but not a selective (citalopram), serotonin reuptake inhibitor is effective in the prophylactic treatment of chronic tension-type headache
}

\author{
Lars Bendtsen, Rigmor Jensen, Jes Olesen
}

\begin{abstract}
Objectives-Although the tricyclic antidepressant amitriptyline is extensively used in the prophylactic treatment of chronic tension-type headache, only few studies have investigated the efficacy of this treatment and the results are contradictory. In addition, the new selective serotonin reuptake inhibiting antidepressants, which are widely used in depression and of potential value in pain management, have never been investigated in a placebo controlled study of tension-type headache. The aim was to evaluate the efficacy of amitriptyline and of the selective serotonin reuptake inhibitor citalopram in chronic tensiontype headache.

Methods-Forty non-depressed patients with chronic tension type headache were included in a 32 week, double blind, placebo controlled, threeway crossover study.

Results-Thirty four patients completed the trial. Amitriptyline reduced area under the headache curve by $30 \%$ compared with placebo $(P=0.002)$, whereas citalopram had no significant effect $(\mathbf{P}=$ 0.68). Explanatory analyses showed that amitriptyline significantly reduced the duration of headache $(P=0.01)$,

cerned, the most important type of headache. ${ }^{1}$ Yet remarkably little is known about its pathophysiology and the treatment available is limited. The only established prophylactic treatment is the tricyclic antidepressant amitriptyline, ${ }^{2}$ a non-selective serotonin reuptake inhibitor. The efficacy of this treatment has, however, only been investigated in a few placebo controlled studies, ${ }^{3-6}$ which have reported conflicting results. The scientific support for the widespread use of amitriptyline in the treatment of chronic tension-type headache, therefore, is scant.

The mechanism of action of amitriptyline in chronic tension-type headache, as well as in other non-depressive chronic pain states, is largely unknown, but it is assumed that the blockage of serotonin reuptake in the CNS plays an essential part in its analgesic effect. ${ }^{7-10}$ The selective serotonin reuptake inhibitor citalopram, which has antidepressant properties comparable with the tricyclic drugs but a far better side effect profile, ${ }^{11}$ might therefore be of value in the treatment of chronic tension type headache. In addition, a comparison of amitriptyline and citalopram could provide information on the mechanism of action of these drugs in chronic pain. The aim of the present study was to evaluate the prophylactic effect of amitriptyline and citalopram in chronic tension-type headache.
\end{abstract} headache frequency $(P=0.01)$, and intake of analgesics $(P=0.02)$ but not headache intensity $(P=0 \cdot 12)$.

Conclusion-Although amitriptyline did not eliminate the headache, it provided a clinically important reduction of headache in the majority of otherwise treatment resistant patients. The differential effect of amitriptyline and citalopram indicates that mechanisms other than inhibition of serotonin reuptake are involved in the analgesic effect of the tricyclic antidepressants. Amitriptyline, but not citalopram, is valuable in the prophylactic treatment of chronic tension type headache.

(F Neurol Neurosurg Psychiatry 1996;61:285-290)

Keywords: antidepressants; pain; tension type headache

Tension type headache is the most common and, as far as socioeconomic impact is con-

\section{Materials and methods}

PATIENTS

Forty patients with chronic tension type headache diagnosed according to the criteria of the International Headache Society ${ }^{12}$ were recruited from the outpatient headache clinic at Glostrup University Hospital, Copenhagen, Denmark. Seven patients had coexisting infrequent migraine ( $\leqslant$ one day a month) whereas 33 never had migraine. The patients underwent a general and a neurological examination, including 12 channel ECG and laboratory screening, and completed a diagnostic headache diary ${ }^{13}$ during a four week run in period. Table 1 gives detailed clinical information.

The inclusion criteria were a diagnosis of chronic tension type headache and age between 18 and 65 years. Women of childbearing potential had to use adequate contraceptive measures throughout the study. The exclusion criteria were previous participation in a clinical trial, migraine more than one day a 
Table 1 Clinical characteristics

\begin{tabular}{lcc}
\hline & Patients included & $\begin{array}{c}\text { Patients who } \\
\text { completed the study }\end{array}$ \\
\hline No of patients & 40 & 34 \\
Sex (women/men) & $25 / 15$ & $22 / 12$ \\
Age (y) & $40 \cdot 0(18-60)$ & $40 \cdot 7(18-60)$ \\
Area under the headache curve & $982(145-3331)$ & $973(145-3331)$ \\
Headache duration (hours/four weeks) & $217(27-487)$ & $220(27-487)$ \\
Headache intensity & $4 \cdot 2(1 \cdot 8-7 \cdot 3)$ & $4 \cdot 1(1 \cdot 8-7 \cdot 3)$ \\
Headache frequency (days/four weeks) & $24 \cdot 5(16-28)$ & $24 \cdot 7(16-28)$ \\
Analgesics (doses/four weeks) & $41 \cdot 8(0-106)$ & $41 \cdot 3(0-93)$ \\
Hamilton depression score & $3 \cdot 3(2-11)$ & $3 \cdot 5(2-11)$ \\
Years with headache & $12 \cdot 2(1-36)$ & $11 \cdot 7(1-36)$ \\
Frequency of migraine (days/year $(\mathrm{n}=7))$ & $7 \cdot 6(2-12)$ & $7 \cdot 6(2-12)$ \\
\hline
\end{tabular}

Values are means (range). There were no significant differences in any of the clinical characteristics between the 34 patients who completed the study and the six drop outs $(P=0 \cdot 32-0 \cdot 98)$

month, serious somatic or psychiatric diseases including depression (Hamilton depression score $^{14} \geqslant 17$ ), misuse of simple analgesics (corresponding to more than $2 \mathrm{~g}$ aspirin a day), regular intake of opiates or benzodiazepines, and previous treatment with antidepressants. All patients gave written informed consent to participate in the study, which was approved by the regional ethics committee. The patients were informed that the study included placebo periods, but no further information about the study design was given.

\section{STUDY DESIGN AND MEDICATION}

The study was designed as a double blind, placebo controlled, three way crossover trial. After a four week run in period, the patients were randomly allocated to one of the six possible treatment sequences (fig 1). Randomisation was done in blocks of six patients. Each of the three drugs was given for eight weeks and the treatment periods were separated by twoweek wash out periods.

The study medication was tablets containing $25 \mathrm{mg}$ or $50 \mathrm{mg}$ amitriptyline (Saroten ${ }^{\circledR}$ ), tablets containing $20 \mathrm{mg}$ citalopram $\left(\right.$ Cipramil $\left.{ }^{(}\right)$, and placebo tablets. In the first week of treatment with amitriptyline the patients received a daily dose of one $25 \mathrm{mg}$ amitriptyline tablet and one placebo tablet, in the second week they received two $25 \mathrm{mg}$ amitriptyline tablets, and in weeks 3-8 they received one $25 \mathrm{mg}$ and one $50 \mathrm{mg}$ amitriptyline tablet corresponding to a daily dose of 75 $\mathrm{mg}$ amitriptyline. During the eight weeks of treatment with citalopram the patients received a daily dose of one citalopram tablet and one placebo tablet corresponding to a daily dose of $20 \mathrm{mg}$ citalopram. During the eight weeks of treatment with placebo and during the wash out periods the patients received a daily dose of two placebo tablets. The patients thus received two tablets daily during all 28 weeks of treatment. All tablets were of identical look and taste, and the patients were told to take the tablets two to three hours before bedtime.

\section{RECORDING OF EFFICACY VARIABLES}

Throughout the study the patients kept a headache diary with recordings of intensity and duration of headache, intake of analgesics, and side effects. Intensity was recorded on an 11 point scale $(0-10)$, in which 0 indicated the headache free condition, 5 indicated a moderate headache, and 10 indicated the worst headache imaginable. Localisation and quality of the headache, whether the headache was aggravated by physical activity, and presence or absence of nausea, photophobia, and phonophobia were also recorded.

\section{CLINICAL VISITS}

Follow up visits were performed at four-week intervals (fig 1). At each visit, the headache diary was checked, medication supplies were handed over, side effects reported by the patients were recorded, and compliance was
Figure 1 Study design of the 32 week, double blind, placebo controlled, three way crossover trial. Each patient was randomly allocated to one of the six treatment sequences a-f. Clinical visits are indicated by ${ }^{*}$.
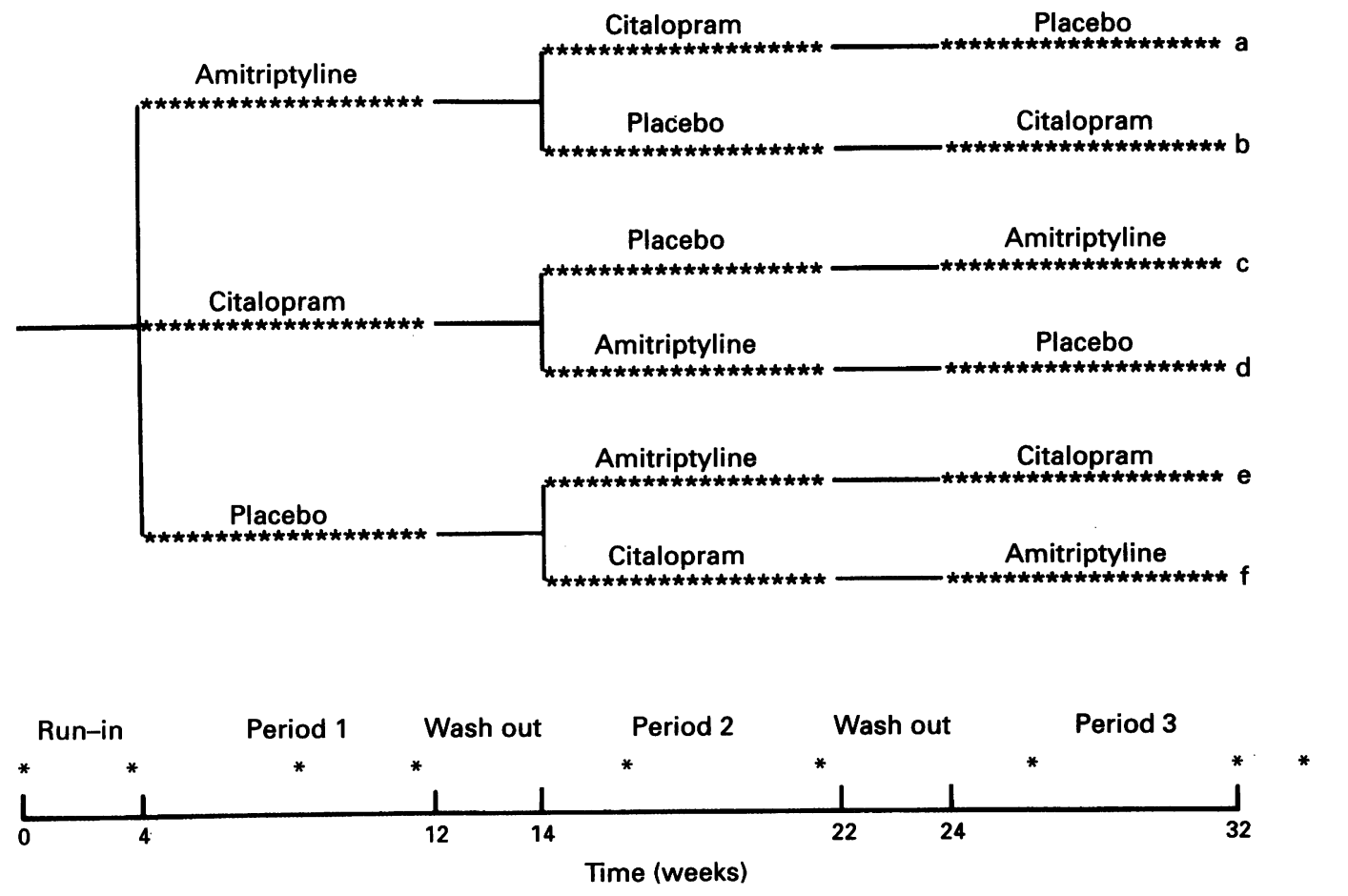
Figure 2 Area under the headache curve (duration $x$ intensity) in 34 patients with chronic tension type headache during eight weeks of treatment with amitriptyline (circles), citalopram (triangles), and placebo (squares). Asterisks indicate significant differences between amitriptyline and placebo. ${ }^{\star} P=0.02$; ${ }^{\star *} P \leqslant 0.008$ $\star * * P=0.001$

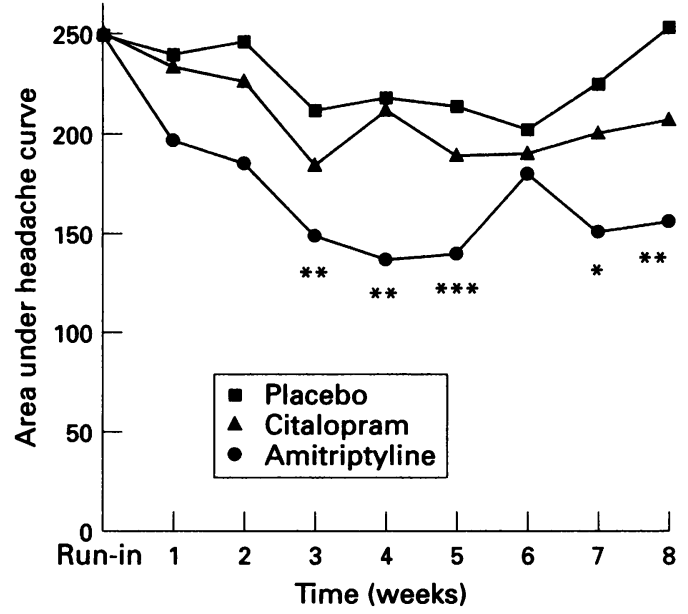

tested by asking the patients whether they remembered to take the tablets regularly.

\section{EVALUATION OF EFFICACY}

The efficacy variables were determined in advance. The primary efficacy variable was the area under the headache curve (AUC) recorded in the last four weeks of each treatment period. The AUC was calculated as the sum of the daily recordings of headache duration $x$ headache intensity. Secondary efficacy variables were $(a)$ headache duration in the last four weeks of each treatment period, (b) mean headache intensity per headache day, $(c)$ headache frequency in the last four weeks of each treatment period, (d) number of analgesic doses, equivalent to $500 \mathrm{mg}$ aspirin, taken in the last four weeks of each treatment period, and $(e)$ number of patients reporting side effects in each treatment period. The efficacy of amitriptyline compared with placebo was calculated as: efficacy $=\left(1-\right.$ AUC $_{\text {amitriptyline }} /$ $\left.\mathrm{AUC}_{\text {placebo }}\right) \times 100 \%$.

\section{STATISTICS}

Results are presented as mean (SEM). Patients who dropped out of the study were excluded from the analyses except when calculating side effects. Friedman's two way test was used to compare efficacy variables among the three drugs. If Friedman's test showed a significant difference between groups, the groups were compared with Wilcoxon's paired rank sum test. To correct for multiple testing the $P$ values were multiplied according to the method of Bonferroni. ${ }^{15}$ Ninety five per cent confidence intervals (95\% CIs) are given. Migraine days were excluded from the analyses. A possible carryover effect was tested for by comparing mean AUC recorded in periods when drug $A$ was followed by drug $B$ with mean AUC in periods when drug $B$ was followed by drug A by means of the Mann-
Whitney two tailed test. ${ }^{15}$ A possible time/period effect was tested for by comparing the difference in AUC in periods when drug A was followed by drug $B$ with the negative difference in AUC in periods when drug B was followed by drug A. ${ }^{15}$ Comparison of clinical characteristics between patients who completed the study and drop outs was done by Mann-Whitney $U$ test. Comparison of clinical characteristics between the groups of patients allocated to the six different treatment sequences was made by Kruskal-Wallis test. McNemar's test was used for comparison of the number of patients reporting side effects. Spearman's test was used for calculation of correlation coefficients, $R$. Two sided $\mathrm{P}$ values were calculated and significance was accepted at the $5 \%$ level.

\section{Results}

TREATMENT EFFECT: PRIMARY VARIABLE

In the 34 patients who completed the study, the area under the headache curve (AUC) was 973 (136) in the run in period, 616 (129) during treatment with amitriptyline, 772 (142) during treatment with citalopram, and 877 (171) during treatment with placebo. Placebo decreased AUC by $10 \%$ compared with the run in period $(P=0 \cdot 12)$. There was a significant difference in AUC among the three treatment groups $(P=0.003)$. The AUC was $30 \%$ lower on amitriptyline than on placebo $(\mathrm{P}=$ 0.002). The absolute difference between amitriptyline and placebo was 261 (95\% CI 103-419). In the 27 patients who had never had migraine, the AUC was $28 \%$ lower on amitriptyline than on placebo $(P=0.002)$. The AUC was $12 \%$ lower on citalopram than on placebo $(P=0.68)$. The absolute difference between citalopram and placebo was 105 $(-42-253)$. The AUC was $20 \%$ lower on amitriptyline than on citalopram $(P=0.12(P=$ 0.04 without Bonferroni correction)). The absolute difference between amitriptyline and citalopram was 156 (95\% CI 36-275). Figure 2 shows the course of headache over time for each treatment. The effect of amitriptyline was significant already in week 3 (the first week of treatment with full dose), and continued to be significant in the rest of the treatment period except for week 6 . There was no carryover effect ( $P=0.06$ to 0.39 ) or time period effect $(P=0.63$ to 1.00$)$.

\section{TREATMENT EFFECT: SECONDARY VARIABLES}

Table 2 presents the secondary efficacy variables. The effect of amitriptyline was primarily due to a decrease in duration of headache $(P=$ 0.01 ), whereas headache intensity decreased only marginally $(P=0 \cdot 12)$. In addition,

Table 2 Treatment effects, secondary variables

\begin{tabular}{lccrc}
\hline & Run in & Amitriptyline & Citalopram & Placebo \\
\hline Headache duration (hours/four weeks) & $220(25)$ & $151(24)^{\star \star}$ & $182(26)$ & $184(27)$ \\
Headache intensity & $4 \cdot 1(0 \cdot 2)$ & $3 \cdot 8(0 \cdot 3)$ & $3 \cdot 6(0 \cdot 3)$ & $3 \cdot 9(0 \cdot 3)$ \\
Headache frequency (days/four weeks) & $24 \cdot 7(0 \cdot 7)$ & $18 \cdot 6(1 \cdot 6)^{\star \star}$ & $21 \cdot 5(1 \cdot 4)$ & $21 \cdot 7(1 \cdot 3)$ \\
Intake of analgesics (doses/four weeks) & $41 \cdot 3(5 \cdot 1)$ & $25 \cdot 3(4 \cdot 2)^{\star}$ & $34 \cdot 8(5 \cdot 7)$ & $33 \cdot 8(5 \cdot 2)$ \\
\hline
\end{tabular}

Values are means $(\mathrm{SEM}) .{ }^{\star} \mathrm{P}=0.02 ;{ }^{\star} \mathrm{P}=0.01 ;$ amitriptyline $v$ placebo $(\mathrm{n}=34)$. 
Table 3 Side effects

\begin{tabular}{llcc}
\hline & Amitriptyline & Citalopram & Placebo \\
\hline Dry mouth & $30^{\star \star \star}$ & 5 & 3 \\
Drowsiness & $21^{\star \star \star}$ & 7 & 6 \\
Dizziness & 7 & 2 & 4 \\
Nausea & 1 & 6 & 3 \\
Obstipation & 3 & 1 & 0 \\
Weight gain & 5 & 0 & 4 \\
Sleep disturbances & 0 & 1 & 3 \\
Abdominal pain & 0 & 1 & 7 \\
Various & 9 & 5 & 15 \\
Number of patients reporting & $33^{\star \star \star}$ & 15 & 4 \\
\hline
\end{tabular}

The number of patients reporting side effects during each of the three treatments are given $\star \star \star \mathrm{P}<0.001$; amitriptyline $v$ placebo; amitriptyline $v$ citalopram. There was no significant difference between citalopram and placebo $(n=40)$.

headache frequency and intake of analgesics were decreased significantly by amitriptyline $(P=0.01$ and $P=0.02$ respectively).

\section{SIDE EFFECTS AND DROP OUTS}

None of the clinical characteristics presented in table 1 differed between the 34 patients who completed the study and the six drop outs ( $P$ $=0.32$ to 0.98 ) or between the groups of patients allocated to the six different treatment sequences $(P=0.20$ to 0.89$)$. The reasons for drop out were side effects (one patient on amitriptyline reporting drowsiness, dizziness, and dry mouth), pregnancy (one patient on placebo), and lack of effect (two patients on placebo and two on citalopram). All drop outs occurred during the first treatment period, except for one patient who dropped out because of lack of effect of citalopram in the second treatment period after having been virtually headache free on amitriptyline.

Amitriptyline induced significantly more side effects than both citalopram and placebo $(P<0.001)$, whereas there was no difference between citalopram and placebo $(P>0.2$; table 3). The difference between amitriptyline and placebo was due to a higher number of patients complaining of dry mouth $(P<0.001)$ and of drowsiness $(P<0.001)$ during the former treatment. Six patients had a total of 19 days with migraine during the 28 weeks of treatment. There was no difference in the number of migraine days among the three treatments $(P=0.50)$.

\section{RELATION BETWEEN EFFICACY AND CLINICAL CHARACTERISTICS}

Of the 34 patients who completed the study, 27 had a better effect from amitriptyline than from placebo. No significant correlations or tendencies were detected between the efficacy of amitriptyline and any of the clinical characteristics listed in table $1(R=0.19$ to $0.23, P=$ 0.25 to 0.95 ). The efficacy of amitriptyline did not differ between women and men ( $P=$ $0 \cdot 59)$.

\section{Discussion \\ EFFICACY AND TOLERABILITY OF \\ AMITRIPTYLINE}

The placebo effect must be taken into account in any study of treatment for headache ${ }^{2}$ and therefore only placebo controlled studies will be discussed here. Lance and Curran ${ }^{3}$ and
Diamond and Baltes ${ }^{4}$ reported superiority of amitriptyline over placebo. The studies are important as they are the first ones in this field, but none of them meet modern methodological standards and they should therefore be interpreted with care. Recently, Göbel et al ${ }^{6}$ evaluated amitriptyline in chronic tension type headache. Compared with placebo, duration of headache was reduced only in the last week of the six week study while the intake of analgesics was unaltered. Unfortunately, the study was of short duration, it did not include a run in period, and neither frequency nor intensity of headache were presented. Nevertheless, as headache duration decreased consistently throughout all six weeks of active treatment but not throughout placebo treatment, the study indicates that amitriptyline has an effect in chronic tension type headache. By contrast with the above studies, a recent multicentre study by Pfaffenrath et $a l^{5}$ could not detect any differences between amitriptyline, amitriptylinoxide, and placebo in chronic tension type headache. However, the frequencies of side effects were similar on amitriptyline and placebo. Usually, amitriptyline has pronounced side effects and the inability to detect known side effects suggests insensitivity of the trial for reasons which remain obscure.

The present study shows a highly significant effect of amitriptyline in chronic tension type headache. The effect was found both for the primary efficacy variable and for a range of secondary efficacy variables. The mean total relief on amitriptyline was $30 \%$ compared with placebo. Amitriptyline, therefore, did not completely alleviate the patients headache, but in evaluating the size of the effect it must be remembered that the patients had had tension type headache for many years and had tried numerous other treatments. They thus represented a rather severe, treatment resistant group. Given also that patients with depression were excluded from this trial, we find the improvement obtained on amitriptyline impressive. Amitriptyline induced far more side effects than placebo but they were generally mild and the number of drop outs was actually lower on amitriptyline than on placebo.

How can the physician identify the patients who will benefit from amitriptyline? Our results indicate that the efficacy of amitriptyline cannot be predicted on the basis of clinical characteristics. Nevertheless, the present finding of a clear and early treatment effect combined with mild side effects suggests that all patients with chronic tension-type headache should have a trial of amitriptyline. In the present trial all patients received a fixed daily dose of $75 \mathrm{mg}$. It is, however, a common clinical experience that many patients respond well to a daily dose of 25 or $50 \mathrm{mg}$ amitriptyline and that only very few patients benefit from increasing the dose above $75 \mathrm{mg}$. In the absence of dose response studies, we recommend starting with $25 \mathrm{mg}$, increasing the dose every 14 th day depending on effect and side effects. The maintenance dose is usually 50 or $75 \mathrm{mg}$ daily. The efficacy of prolonged treat- 
ment of tension type headache with amitriptyline has never been investigated and such studies are much needed. On the basis of clinical experience, we suggest that a successful treatment should be discontinued after six months to one year and that treatment should be restarted in the event of relapse.

\section{EFFICACY AND TOLERABILITY OF CITALOPRAM} The new selective serotonin reuptake inhibitors are of potential value in the management of chronic pain, but only a few placebo controlled studies have been performed. ${ }^{16}$ These studies have shown moderate ${ }^{17-20}$ or no effects $^{2122}$ of the selective serotonin reuptake inhibitors, which is in line with the present study. We found a non-significant trend towards an effect of citalopram as all variables, except intake of analgesics, were improved during treatment with citalopram compared with placebo. In addition, the AUC was lower during all of the eight weeks of treatment with citalopram compared with placebo. A significant effect of citalopram might therefore possibly have been detected, if we had examined a larger number of patients. Thirty four patients, however, provide comfortable power in a crossover study, which is $5-10$ times as powerful as a parallel study. ${ }^{23}$ Even if an effect could be shown in a larger study it is therefore unlikely to be clinically relevant.

Saper $e t a l^{20}$ reported the selective serotonin reuptake inhibitor fluoxetine to be moderately effective in patients with so-called chronic daily headache. Their patients could have migraine twice a week, which makes it difficult to compare the two studies. Infrequent coexisting migraine does not seem to indicate a more favourable response to citalopram, as the seven patients with coexisting infrequent migraine were improved less $(0 \%)$ on citalopram than the 27 patients who had never had migraine $(14 \%)$ in the present study.

We used a fixed daily dose of $20 \mathrm{mg}$ citalopram-that is, the lowest dose recommended for the treatment of depression. By comparison, we used half of the lowest dose of amitriptyline recommended for the treatment of depression. We cannot exclude the possibility that a better effect would have been obtained with a higher dose of citalopram, but previous studies in other pain disorders contradict this. ${ }^{1922}$ Despite the excellent side effect profile, citalopram (and probably also other selective serotonin reuptake inhibitors) cannot be recommended in the treatment of chronic tension-type headache.

\section{METHODOLOGICAL CONSIDERATIONS}

The selection of efficacy variables in clinical trials on tension-type headache is difficult. ${ }^{24}$ The International Headache Society Committee on Clinical Trials ${ }^{24}$ suggests that frequency of headache should be used as the primary efficacy variable. However, this rates headache days lasting, for example, $30 \mathrm{~min}$ utes and 16 hours the same. ${ }^{6}$ To the patients, the duration and the severity of their headache are the most important features and AUC is therefore the clinically most relevant variable.
In addition, calculation of an area under a curve is a statistically valid and simple method for analysing serial measurements. ${ }^{25}$ Unfortunately, the multiplication of two variables conceals some information and it is therefore essential also to present duration, intensity, and frequency of headache, as well as intake of analgesics. Until further methodological studies have identified the best efficacy variable, future studies should select in advance one of the above mentioned variables as the primary efficacy variable ${ }^{24}$ and present the others as secondary variables.

The clearly identifiable side effects of the tricyclic antidepressants make effective blinding difficult. We found, however, the three way crossover design very useful in this regard. Generally, the patients thought that the medications changed many times during the trial and also the observer, who knew the design, was effectively blinded because of the many possible treatment sequences. In addition, the side effects were usually most prominent in the first week of treatment and then gradually decreased, contrary to the treatment effect. Although we did not formally record data on efficacy of blinding, we are assured that the blinding was effective in this study.

\section{MODE OF ACTION}

There is general agreement that the analgesic effect of the tricyclic drugs is independent of their antidepressant effect ${ }^{26-29}$ and this was supported by the present finding of an effect of amitriptyline in non-depressed patients with headache. The mechanism of action is, however, not clarified. Previously it was assumed that the analgesic properties of the tricyclic antidepressants could be ascribed to the blockage of serotonin reuptake in the CNS, ${ }^{7-10}$ but this has recently been questioned. In an animal model, Ardid et al ${ }^{30}$ found that both noradrenaline reuptake inhibitors and selective serotonin reuptake inhibitors had analgesic effects, but that amitriptyline was more effective than both of these drugs. Watson and Evans $^{31}$ found amitriptyline more effective than the selective serotonin reuptake inhibitor zimeldine in postherpetic neuralgia, and Sindrup et al $^{18}$ reported that the tricyclic antidepressant imipramine was more effective than the selective serotonin reuptake inhibitor paroxetine in diabetic neuropathy. These results are in line with the present finding of a clear effect of amitriptyline but only a trend towards an effect of citalopram in tension-type headache. Together the present and previous studies indicate that the selective serotonin reuptake inhibitors are less effective than the tricyclic antidepressants in pain management. Whereas citalopram is an extremely specific serotonin reuptake inhibitor, ${ }^{32}$ amitriptyline also has effects on reuptake of noradrenaline ${ }^{33}$ as well as effects on serotonergic, ${ }^{34}$ adrenergic, ${ }^{35}$ cholinergic, ${ }^{34}$ and histaminergic ${ }^{36}$ receptors. Of these effects, inhibition of noradrenaline reuptake ${ }^{33}$ and activation of various serotonin receptor subtypes ${ }^{37}$ may be especially important. The present study does not allow any firm conclusions on this issue, 
but it indicates that mechanisms other than inhibition of serotonin reuptake are involved in the analgesic effect of the tricyclic antidepressants.

We thank Mrs Hanne Andresen for skilful technical assistance and $H$ Lundbeck for providing the medication. The study was supported by the Lundbeck Foundation (145/91)

1 Rasmussen BK, Jensen R, Olesen J. Impact of headache on sickness absence and utilisation of medical services: a Danish population study. $\mathcal{J}$ Epidemiol Community Health 1992;46:443-6.

2 Couch JR, Micieli G. Prophylactic Pharmacotherapy. In: Olesen J, Tfelt-Hansen P, Welch KMA, eds. The Olesen J, Tfelt-Hansen P, Welch KMA,
headaches. New York: Raven Press 1993:537-42.

3 Lance JW, Curran DA. Treatment of chronic tension headache. Lancet 1964; i:1236-9.

4 Diamond S, Baltes BJ. Chronic tension headache-treated with amitriptyline-a double-blind study. Headach 1971;11:110-6.

5 Pfaffenrath V, Diener HC, Isler H, et al. Efficacy and tolerability of amitriptylinoxide in the treatment of chronic tension-type headache: a multi-centre controlled study. Cephalalgia 1994;14:149-55.

6 Göbel H, Hamouz V, Hansen C, et al. Chronic tensiontype headache: amitriptyline reduces clinical headacheduration and experimental pain sensitivity but does not alter pericranial muscle activity readings. Pain 1994; 59:241-9.

7 Botney M, Fields HL. Amitriptyline potentiates morphine analgesia by a direct action on the central nervous sysanalgesia by a direct action on
tem. Ann Neurol 1983;13:160-4.

8 Tollison CD, Kriegel ML. Selected tricyclic antidepressants in the management of chronic benign pain. South Med F 1988;81:562-4.

9 Tura B, Tura SM. The analgesic effect of tricyclic antidepressants. Brain Res 1990;518:19-22.

10 Sacerdote P, Brini A, Mantegazza P, Panerai AE. A role for serotonin and beta-endorphin in the analgesia induced by some tricyclic antidepressant drugs. Pharmacol Biochem Behav 1987;26:153-8.

11 Bech $P$, Cialdella P. Citalopram in depression-metaanalysis of intended and unintended effects. Int Clin Psychopharmacol 1992;6:45-54.

12 Headache Classification Committee of the International Headache Society. Classification and diagnostic criteria for headache disorders, cranial neuralgias and facial pain. Cephalalgia 1988:8 suppl 7, 1-96.

13 Russell MB, Rasmussen BK, Brennum J, Iversen HK, Jensen RA, Olesen J. Presentation of a new instrument: the diagnostic headache diary. Cephalalgia 1992;12: 369-74.

14 Hamilton M. A rating scale for depression. I Neurol Neurosurg Psychiatry1960;23:56-62.

15 Altman DG. Practical statistics for medical research. London: Chapman and Hall, 1991

16 Magni G. The use of antidepressants in the treatment of chronic pain. A review of the current evidence. Drugs 1991;42:730-48.

17 Johansson F, von Knorring L. A double-blind controlled study of serotonin uptake inhibitor (Zimelidine) versus placebo in chronic pain patients. Pain 1979;7:69-78.

18 Sindrup SH, Gram LF, Brosen K, Eshoj O, Mogensen EF. The selective serotonin reuptake inhibitor paroxetine is effective in the treatment of diabetic neuropathy symptoms. Pain 1990;42:135-44.

19 Sindrup SH, Bjerre U, Dejgaard A, Brosen K, Aaes Jorgensen T, Gram LF. The selective serotonin reuptake inhibitor citalopram relieves the symptoms of diabetic neuropathy. Clin Pharmacol Ther 1992;52: 547-52

20 Saper JR, Silberstein SD, Lake AE, Winters ME. Doubleblind trial of fluoxetine: chronic daily headache and migraine. Headache 1994;34:497-502

21 Max MB, Lynch SA, Muir J, Shoaf SE, Smoller B, Dubner R. Effects of desipramine, amitriptyline, and fluoxetine on pain in diabetic neuropathy. N Engl f Med 1992, 326:1250-6.

22 Nørregaard J, Volkmann H, Danneskiold-Samsoe B. A randomized controlled trial of citalopram in the treatment of fibromyalgia. Pain 1995;61:445-9.

23 Tfelt-Hansen $P$, Olesen J. Methodological aspects of drug trials in migraine. Neuroepidemiology 1985;4: 204-26.

24 International Headache Society Committee on Clinical Trials. Guidelines for trials of drug treatments in tensiontype headache. Cephalalgia 1995;15:165-79.

25 Matthews JN, Altman DG, Campbell MJ, Royston P. Analysis of serial measurements in medical research. $B M \mathscr{F}$ 1990;300:230-5.

26 Sharav Y, Singer E, Schmidt E, Dionne RA, Dubner R. The analgesic effect of amitriptyline on chronic facial pain. Pain 1987;31:199-209.

27 Panerai AE, Monza G, Movilia P, Bianchi M, Francucci $B M$, Tiengo $M$. A randomized, within-patient, crossover, placebo-controlled trial on the efficacy and tolerability of the tricyclic antidepressants chlorimipramine and nortriptyline in central pain. Acta Neurol Scand 1990;82: 34-8.

28 Egbunike IG, Chaffee BJ. Antidepressants in the management of chronic pain syndromes. Pharmacotherapy 1990 ; ment of chron.

29 Onghena P, Van Houdenhove B. Antidepressant-induced analgesia in chronic non-malignant pain: a meta-analysis of 39 placebo-controlled studies. Pain 1992;49:205-19.

30 Ardid D, Marty H, Fialip J, Privat AM, Eschalier A, Lavarenne J. Comparative effects of different uptake nhibitor antidepressants in two pain tests in mice. Fundam Clin Pharmacol 1992;6:75-82.

31 Watson CP, Evans RJ. A comparative trial of amitriptyline and zimelidine in post-herpetic neuralgia. Pain 1985;23 387-94.

32 Hyttel J. Neurochemical characterization of a new potent and selective serotonin uptake inhibitor: $\mathrm{Lu}$ 10-171. Psychopharmacology 1977;51:225-33.

33 Taiwo YO, Fabian A, Pazoles CJ, Fields HL. Potentiation of morphine antinociception by monoamine reuptake morphine antinociception by monoamine reuptake

34 Hyttel J. Citalopram-pharmacological profile of a specific serotonin uptake inhibitor with antidepressant activity. Prog Neuropsychopharmacol Biol Psychiatry 1982;6: 277-95.

35 U'Prichard DC, Greenberg DA, Sheeman PP, Snyder SH. Tricyclic antidepressants: therapeutic properties and affinity for alpha-noradrenergic receptor binding sites in the brain. Science 1978;199:197-9.

36 Sindrup SH, Gram LF, Skjold T, Grodum E, Brosen K, Beck Nielsen $H$. Clomipramine vs desipramine vs placebo in the treatment of diabetic neuropathy symptoms. A double-blind cross-over study $\mathrm{Br} F$ Clin Pharmacol 1990;30:683-91.

37 Glaum SR, Proudfit HK, Anderson EG. Reversal of the antinociceptive effects of intrathecally administered serotonin in the rat by a selective 5-HT-3 receptor antagonist. Neurosci Lett 1988;95:313-7. 